\author{
THEORIA ET HISTORIA SCIENTIARUM, VOL. VII, N I \\ Ed. Nicolas Copernicus University 2003
}

\title{
Shaun Gallagher
}

\section{Bodily self-awareness and object perception}

The term 'proprioception' has a wide range of meanings. Neuroscientists, for example, may treat somatic proprioception as an entirely sub-personal, nonconscious function. In this sense, it delivers information about body posture and limb position, generated in physiological (mechanical) proprioceptors located throughout the body (e.g., Sherrington, 1953; Foumeret and Jeannerod, 1998). In contrast, psychologists and philosophers sometimes treat somatic proprioception as a form of consciousness (e.g., O'Shaughnessy, 1995). One is said to be proprioceptively aware of one's own body, to consciously know where one's limbs are at any particular time as one moves through the world (e.g., Sheets-Johnstone, 1998). Thus proprioception can mean either nonconscious information or a form of conscious awareness. In this paper I maintain the distinction between proprioceptive information and proprioceptive awareness, respectively. ${ }^{1}$

Proprioceptive information and proprioceptive awareness are closely related, and together they form a standard, but narrow and specifically intracorporeal definition of somatic proprioception. Narrow, because proprioception is also taken in a much more general sense by Gibsonian psychologists. In this latter sense it means a self-awareness that belongs to any modality of perception (vision, touch, hearing and so on). Generally, perceptual experience comes along with a sense of body posture and movement relative to the environment, and a corresponding sense of self, which Neisser (1988) terms the 'ecological self'. This ecological proprioception is normally integrated with different modalities of sensory information concerning one's own body as a moving agent in the environment, and with the intracorporeal information and awareness provided by somatic proprioception (Trevarthen, 1986).

\footnotetext{
${ }^{1}$ For more on the distinction between proprioceptive information and proprioceptive awareness see the Introduction to Bermudez, Marcel, and Eilan (1995), and Bermudez (1998).
} 
In both psychological and philosophical discussions proprioceptive awareness is often considered to be a form of object-perception in which one identifies one's body as an object (Bermudez, 1998; Gibson, 1979; O'Shaughnessy, 1995). Alternatively, it is also possible that proprioceptive awareness can function as a non-perceptual or non-observational self-awareness (Shoemaker, 1984), and as such it might be regarded as a more immediate and reliable form of awareness than object-perception.

In this paper I would like to argue that proprioceptive awareness (including both somatic and ecological proprioception) is primarily a form of non-perceptual awareness. This might seem to be an obscure point, but it turns out to be philosophically significant in regard to what Shoemaker calls 'immunity to error through misidentification'. Although it is possible to make a mistake in identifying one's body via sense-perceptual modalities such as vision, some philosophers argue that one is immune to error through misidentification in regard to knowing one's own body by means of proprioception (Cassam, 1995; Evans, 1982). If proprioception were a form of perception then it would be possible for one to proprioceptively misidentify oneself in referring to one's body. In arguing that proprioception is not a form of perception I am defending the immunity principle in this regard.

\section{Proprioceptive Awareness and Object Perception}

To begin we need to agree on what perception is. Here, we are fortunate to find that theorists who argue that proprioception is a form of perception and theorists who maintain that it is not, do not necessarily disagree on what perception is. For purposes of this paper, I will join this consensus and adopt what Shoemaker (1994) calls the 'object perception model'. On this model perception necessarily involves a relation to an object, or to some state of affairs that ultimately depends on an experience that is directed at one or more objects. One distinctive feature of this model involves the "identification constraint" (Bermudez, 1998, p. 136). The identification constraint states that sense perception involves information that affords the identification of the object. Sense perception allows the perceiver to distinguish or pick out one object among others; it allows for "tracking" and reidentification of the object over time (Shoemaker, 1994; Bermudez, 1998). A form of awareness that does not meet the identification constraint, by definition, is not perceptual awareness. I will argue, on phenomenological grounds, that proprioceptive awareness in its most typical form does not meet the identification constraint.

Furthermore, without exception, perceptions that involve a differential spatial order (perceptions in the sense modalities of vision, touch, audition, and smell) 
do so in terms of an egocentric (body-centered, perspectival) spatial framework. Perception in this regard is necessarily embodied. If there is a form of body awareness that captures the differential spatial order of the body but does not involve an egocentric spatial framework, then that awareness would be nonperceptual. I argue here that proprioceptive awareness in its most typical form does not involve an egocentric framework. Since proprioceptive awareness in its most typical form fails to meet either of these constraints it can not be a case of perception; rather it counts as a form of non-perceptual awareness.

The qualification that I place on proprioception here is important. In its "most typical form" proprioception is, as O'Shaughnessy points out, "attentively recessive" (1995, p. 175). In other words, when I am engaged in the world, I tend not to notice my posture or specific movements of my limbs. In its most typical form it provides a non-reflective ${ }^{23}$ awareness of the body. It is possible, however, to transform proprioception into an attentive reflective awareness in which I "involute" my attention to some particular part of my body. I can attend, for example, without vision or any other sense except proprioception, to the position or movement of my foot. ${ }^{3} \mathrm{O}$ 'Shaughnessy admits that this would be an atypical case of proprioception (he calls it reflexive or introspective proprioception), but claims, wrongly I think, that it differs little from recessive, non- reflective (or "instrumental") examples, and that proprioceptive awareness in general is indeed a form of perception.

In opposition to the idea that proprioceptive awareness is perceptual awareness, it is important to realize that proprioceptive awareness does not involve the right kind of identifying relation to an object. First, what does it mean for perception to necessarily involve a relation to an object? What kind of relation is involved? One might think that the relation at stake is a spatial and/or temporal relation. Roughly (stars and heavenly bodies to the contrary), for something to be perceived it must be located relatively close by; and it has to be simultaneous or close to simultaneous with the perceptual act. It has to be in a certain objective proximity to the perceiving organism to be perceived. But the relation to an object that is claimed for perception is something more than this. Object perception involves an experience that is directed at the object. The relation at stake here is

2 Various authors call this awareness 'pre-reflective' (Merleau-Ponty), non-positional or non- thetic (Sartre), or non-observational (Shoemaker).

${ }^{3}$ For qualifications on this claim see Kinsbourne (1995, p. 213). It is often difficult to sort out specifically proprioceptive aspects from aspects of experience that involve touch, muscle stress, skin stretch and other bodily sensations. One circumstance in which one might isolate proprioceptive awareness is when floating in a swimming pool. Without one's relaxed legs touching one another it is still possible to be aware of the relative position of one's legs - e.g., that they are or are not crossed. 
what phenomenologists like Brentano and Husserl call an intentional relation. For perception it is not enough that objects are in the right objective proximity with the perceiving organism. Perception is in some sense "directed at" an object.

On the object perception model, for an intentional relation to be a perceptual relation, one necessary (although not sufficient) condition is that the intentional relation involves the identification of the object as something. It is possible that although something is in the right objective proximity, and indeed in one's direct line of vision, it is still not perceived (e.g., a recognizable shape embedded in a "noisy" context). To perceive involves the ability to pick something out, to identify it as an object or as a state of affairs in some minimal sense. Does proprioception identify the body as an object in this sense?

It is possible to have an awareness of the body with perceptual content that references the body as an object. This may be the result of a perceptual act that attends to the body as its explicit object, as in a reflective self-examination. This kind of perception picks the body out (identifies it) as the object on which to focus, and in so doing it explicitly discriminates between the body and other objects in the environment. This kind of bodily awareness, which may include a reflexive ("involuted") proprioception, does identify the body, or part of the body, as an object and in this sense is perceptual.

There are also times when I may be involved in some project in which my attention is focused on some thing or state of affairs other than my body, and at the same time I am aware of what my body is doing. Some theorists maintain that even in these circumstances this marginal awareness of the body is a perceptual awareness; that the body remains present in the field of consciousness, and that this presence is perceptual in nature (e.g., Armstrong, 1968; Chisholm, 1969). On this account perceptions of things or states of affairs involve a simultaneous perception of the body. Consider a recent statement of this idea.

The best description of the phenomenology of touch is that tactile experience is always both exteroceptive and proprioceptive. Attention can be directed either proprioceptively or exteroceptively, and it can be shifted from one to the other, but this should be viewed as an alteration of the balance between focal and peripheral awareness. When attention is directed exteroceptively toward the spatial properties of an object, the perceiver remains peripherally aware of the spatial properties of the relevant limb [that is, the limb involved in touching or haptically exploring the object], and vice versa. (Bermudez, 1998, p. 139).

This observation is part of an argument designed by Bermudez to show that proprioceptive awareness, which includes complex information about the body, is a form of perception. The observation is made in relation to the following example. If I touch and manipulate a certain thing, for example, a book, I gain a sense of its shape through the changing spatial properties of my fingers. I can 
easily shift my attention between the shape of the book and the contours of my fingers. Both my fingers and the book appear in the perceptual field. When my focus is on the book, my fingers remain in peripheral awareness; and when my fingers are brought into attentional focus, the book shifts to the peripheral field. It seems right to claim that both body and book are perceived, and that this is a particular instance of a more general condition, namely, that the body is always in the perceptual field.

But let's consider the phenomenology more closely. When I shift my attention away from the book to my fingers, then that very act of attention brings my body into an objective presence, as something perceptually identifiable. This works equally well for visual or proprioceptive attention. In the latter case, however, this shift of attention, would generate an involuted, proprioceptive awareness of my fingers that originally plays no part in the perception of the book. Indeed, it interrupts that perception. When my attention is shifted toward my body, I do in fact identify my body as the object of my perception as, for example, I attend to the relative spatial position of my fingers. But when my attention is directed at the book, my awareness of my body is precisely not an identifying awareness of it as an object, that is, it is not a perceptual awareness. As I keep track of the book, I do not have to keep track of my hands.

\section{Proprioception's contribution to perception}

In the action of the perceiving body, when through tactile exploration 1 perceive the shape of a small object that I hold in my hand, proprioception certainly plays a role in guiding my movement. The information developed in this proprioceptive performance contributes to the tactile perception of the object. Two things are to be noted, however. First, the fact that proprioception contributes to tactile perception does not mean that the object is perceived proprioceptively. If proprioception has an object, its object would be, by definition, the body. Second, however, in this process proprioception does not deliver an identifying awareness of the body in the same way that touch delivers an identifying awareness of the object. In fact, much of the proprioceptive contribution to tactile perception never reaches the level of conscious awareness (that is, it remains a form of subpersonal proprioceptive information); whatever does reach the level of proprioceptive awareness remains experientially recessive and does not involve the identification of an object. In this regard, proprioception's reference to the body is as subject rather than as object.

To see this it will help to examine Bermudez's argument more closely. He argues that proprioceptive awareness is perceptual because it does meet the certification constraint. To establish this he claims that proprioception involves 
not just the perception of the body, but plays an important role in the perception of other objects. Part of this claim depends on the following phenomenological description.

Consider an instance of exploratory haptic perception, as when one discerns the shape of an object in the dark by running one's fingers over it. The following ... [is] true of such a perception. First, through one's awareness of the changing spatial properties of one's fingers, one gains an awareness of the spatial properties of the object. (Bermudez, 1998, p. 138).

If one considers this awareness to be perceptual and to involve shifts between focal and peripheral dimensions, as Bermudez suggests, then this claim entails one of two things. Either we perceive the object only by bringing our fingers into focus, thereby pushing the object into the peripheral field. Or, our fingers remain in the periphery and the tactile perception of the object requires that we perceive what is in focus (the object) only by perceiving what is in the periphery (our fingers). On the most charitable reading it cannot be the first, since that would amount to the nonsensical idea that we focus on an object only by keeping it in our peripheral field (that is, by not focusing on it). The second option is not much of an improvement, since that would mean that we focus on an object by attending to something else in the periphery (our fingers).

In contrast to Bermudez, the claim we should make is that in the very act of perceiving, the body is to a high degree experientially transparent. This transparency is not fully captured in the claim that when I attend to the perceived thing the body remains in the peripheral field of perception. To say that the body is in the peripheral proprioceptive field is not equivalent to saying that proprioception is attentively recessive. After all, parts of my body may be in my peripheral visual field, yet this would not mean that vision is attentively recessive. To say that proprioception is attentively recessive means that it provides an awareness, of the body that is tacit or implicit in the body's motor performance. When I am moving I am non-reflectively aware that I am moving, and this nonreflective awareness is not equivalent to a perception of the body as an object in the peripheral field. The awareness that I am moving comes from proprioceptive feedback that functions as an integral part of the continuous movement. I do not discover that I am moving by noticing an object, which happens to be my body, moving in the periphery of my perceptual field.

In the act of perception the perceiving body is always in excess of the body that is perceived. It may be helpful to consider the similarities and differences between vision and proprioception. Are the fingers, as they function in haptic exploration, analogous to objects in peripheral vision, or to the way that the eyes function in vision? Would it be right to say, analogously to Bermudez's suggestion about the touching fingers, that the eyes and their movements are part of the 
peripheral perceptual field? My eyes are obviously not part of my visual field when I see an object, I do not see my eyes, even in peripheral vision. Rather, I see with my eyes. Perhaps, however, if I concentrate in the proper way, I can proprioceptively feel the movement of my eyes as I visually explore the environment. Yet, to the degree that I have to concentrate to achieve a feeling of movement and position sense for the eyes, the eyes are less in the periphery than in the focus of my (now involuted) perceptual field. The movement and position sense for my eyes are normally quite recessive; I have to concentrate intensely and reflectively to attend to them. Indeed, for all practical purposes, in the act of vision I am generally unaware of my eyes. The regular saccadic action of my eyes, and even their regular blinking movements remain unconscious. Proprioceptively, my touching fingers are also attentively recessive unless I reflectively attend to them, which I can do proprioceptively, visually, or again tactilely. Just as I see with my eyes, I touch with my fingers. I touch with my fingers, I have tactile experience, and I perceive the shape of the object in my hand, precisely when I am not perceiving my fingers. The tactile perception of an object is not accomplished through my perceptual awareness of the changing spatial properties of my fingers; awareness of my fingers is not equivalent to my tactile awareness of the object. The body's mode of being in the perceiving act is more than to be perceived.

As part of his argument for treating proprioception as a form of perception Bermudez in addition cites evidence concerning intermodal perception to suggest that the possible objects of proprioception are not limited to the body. Again, satisfying this "multiple object constraint" is a precondition to satisfying the identification constraint, and it would allow for the possibility that proprioceptive awareness is able to discriminate the body from other perceptual objects. What we have said above applies to this part of the argument as well. What the evidence does show is the important intermodal role that proprioception plays in perceptual experience. Vision involves a certain motor control of the eyes that depends on proprioceptive information; haptic touch, and especially in its spatial aspects, involves a certain motor control of the hands that requires proprioceptive feedback. Even more than this, information drawn from the other senses is immediately translatable into proprioceptive information, and vice versa. Such claims about cross-modal integration are certainly true. In this regard, proprioception plays an important role in sense perception. Two things, however, prevent us from concluding that in such cases proprioception is a mode of perception that has multiple objects. First, for the most part, if not in full, what is at stake in these cases is proprioceptive information rather than proprioceptive awareness? The specific proprioceptive

\footnotetext{
${ }^{4}$ Bermudez clearly makes this distinction between proprioceptive awareness and subpersonal proprioceptive information, but he loses track of it in this part of his argument.
} 
contributions to perceptual experience that Bermudez describes are sub-personal. Second, to the degree that proprioceptive awareness may be involved, it is not in the proprioceptive awareness of our hands that we gain awareness of changing spatial properties of the object; rather, touch itself, which is proprioceptively informed, delivers that information. Nor can we say that visual experience of an object is in some way a proprioceptive awareness of an object, even though proprioceptive information plays an important role in the motor control of our eyes, and our vision would be dramatically different without proprioception. Clearly, proprioception shapes sense-perceptual experience, but this is not equivalent to saying that proprioception is a form of perception or that it is a perception of multiple objects. In touch, vision, and the other perceptual senses, the referent of proprioception remains the body (as subject rather than as object).

Bermudez himself notes an important characteristic of somatic proprioception that supports the idea that proprioception does not have multiple objects. Although proprioception is a form of self-awareness that does provide a sense of a differentiation between self and non-self, it does not present a very rich content with reference to the non-self. Somatic proprioception "does not implicate ... a particularly rich conception of what the self is opposed to. The conception of the environment emerging from somatic proprioception need not be anything richer than what is not responsive to the will ..." (Bermudez, 1998, p. 238). This implies, not only that the awareness of the non-self delivered by proprioception does not contain distinctive and multiple objects, but also that the bodily self of which proprioception provides awareness is not taken as one object among others (since, in effect, proprioception does not involve the awareness of other objects). ${ }^{5}$

Cassam suggests that to perceive something as an object may involve something different than identifying it or keeping track of it. First, as O'Shaughnessy (1989) suggests, we might perceive something as an object by experiencing it as having primary qualities or properties such as shape or solidity. If one is aware of the shape or solidity of one's body, this could be a perceptual awareness of it as an object.

One way in which one might be aware of the presence of something solid at a certain location is to discover that one cannot push one's body through it when it is in tactile contact. To experience the solidity of another object in this way is at the same time to be aware of the solidity of one's own body ... (Cassam, 1995, p. 330).

\footnotetext{
5 Bermudez's "symmetry thesis", or more generally, his idea that self-awareness involves a basically contrastive dimension so that the richness of self-awareness is directly proportionate to the richness of the awareness of the environment, implies that proprioception is not an awareness of the body as an object. See Bermudez, 1998, pp. 237ff.
} 
This may be true, but it has little relevance to the issue of whether proprioception is a form of perception, since the experience of the solidity of our body is not a proprioceptive experience. As Cassam suggests, it is a tactile experience. Furthermore, although proprioception provides a sense of posture and limb position, it does not deliver a sense of body shape. If I hold my arm out to the side of my body, I can tell this posture by proprioception, but proprioception is not such to tell me that my arm is of cylindrical shape rather than rectangular. I know this from other senses.

Cassam also suggests that awareness of something as an object might involve awareness of it as something that includes "more than meets the eye" $(1995, \mathrm{p}$. 330). To the extent that we are aware of our body as having hidden parts, we may be aware of it as an object. Again, however, this is not a matter for proprioception so much as it is for vision and what is unavailable for vision. The claim that I am defending in this paper is very specific. Proprioception in its most typical form is not a perceptual awareness, that is, it does not take the body as an object. I do not want to deny that one can perceive one's body by other means.

\section{Spatial Frameworks}

I now turn to the contrast between proprioception and spatial perception with regard to spatial frames of reference. Here we can cite an argument that derives from O'Shaughnessy (1980) and is cited by Bermudez himself in a slightly different context. One of the important functions of the body in the context of perception and action is to provide the basis for an egocentric (or body-centered) spatial frame of reference. Indeed, this egocentric framework is required for the very possibility of action, and for the general structure of perceptual experience. The fact that perception is perspectivally spatial (for example, the book appears to my right or to my left, or in the center of my perceptual field), is a fact that depends precisely on the spatiality of the perceiving body. If one accepts the premise that sense perception of the world is spatially organized by an implicit reference to our bodily position, the awareness that is the basis for that implicit reference cannot be based on perceptual awareness without the threat of infinite regress. This point is closely tied to the notion of the experiential transparency of the body mentioned above, and is nicely stated by Merleau-Ponty. ${ }^{6}$

${ }^{6}$ A similar argument occurs in Sartre (1956, p. 378). The argument is also implicit in Shoemaker ;994a, 1986). 
I observe external objects with my body, I handle them, examine them, walk around them, but my body itself is a thing which I do not observe [in the act of perception]: in order to be able to do so, I should need the use of a second body which itself would be unobservable. (1962, p. 91).

As Bermudez (1995, p. 388) puts it: "If information about the location and orientation of the body is acquired sense-perceptually, then ... it needs to be mapped onto information about the location and orientation of the body." To avoid the infinite regress Bermudez agrees with O'Shaughnessy that one requires a nonperceptual bodily awareness, one that remains "non-attentive, non- conceptual, and insulated from the system of propositional attitudes" (Bermudez, 1995, p. 396). In the normal case this is a form of body awareness that is built into the structures of perception and action but is not itself a perceptual awareness.

Proprioception is a good candidate for being this non-perceptual awareness for one very basic reason, and both O'Shaughnessy and Bermudez, despite their contention that proprioception is a form of perception, help to make the case. O'Shaughnessy, for example, viewing proprioception as a form of perception, notes the following. "Here we encounter a unique situation in perception, and a very strange one at that: namely, the revealed (material object) [the body in the case of proprioception] constitutes the very system of ordering/individuation/differentiation of the revealer (bodily sensations [and their proprioceptively determined locations])" (1995, p. 191). He attributes this to the immediacy of proprioception: the fact that proprioceptive awareness does not attentively mediate the perception of the body; for if it did, it would have an ordering system, a spatial frame of reference that was independent of the body. In this feature, proprioception is different from the forms of spatial perception. Generally speaking, the proprioceptive spatiality of the body is not framed by anything other than the body itself. In other words, proprioception is a nonperspectival awareness of the body.

In contrast, the perceptual spatiality of a perceived object is framed by something other than the perceived object, namely, it is framed in reference to the perceiving body. This is not the case for proprioception, as Bermudez points out. "In contrast with vision, audition, and the other canonically exteroceptive modalities, there are certain spatial notions that do not seem to be applicable to somatic proprioception" (1998, p. 153). Specifically he mentions distance and direction. That is, we can ask about the distance and direction of a perceived object in terms of how far away it is, and in what direction. But these spatial parameters are meaningful only in relation to a frame of reference that has an origin. This does not apply to proprioception. Proprioceptive awareness does not organize the differential spatial order of the body around an origin. Whereas one can say that this book is closer to me than that book over there, one cannot say that my foot is closer to me than my hand. Perception organizes spatial distribu- 
tions around an egocentric frame of reference that is implicitly indexed to the perceiving body, and things appear near or far, to the left or to the right, and so forth, only in relation to the body. ${ }^{7}$ In contrast, proprioception follows the contours of my body, but not from a perspective.

We can say this in a different way. The proprioceptive field is not organized on a relative framework. Although it is possible to say that bodily sensation A is to the left of bodily sensation B, or that sensation A is farther away from sensation $\mathrm{B}$ than is sensation $\mathrm{C}$, this spatiality is not reducible to the perceptual spatial framework. Left, right, center, and distance are spatial parameters that are completely relative in perceptual experience. What is to my right may be to your left. And what is to my right now will be to my left if I turn 180 degrees. But intrabodily parameters are absolute in proprioception. What is proprio- ceptively on the right side of my body is just so, whether my right side is located to your left, or whether I turn. If I move my left hand to touch my right shoulder, it does not become a second right hand. If sensation $\mathrm{A}$ is just this distance from sensation $\mathrm{B}$, I cannot make them closer on the proprioceptive map even if I contort my body to make them objectively closer.

In the case of spatial perception I perceive from a perspective that is indexed to my body. In proprioception I do not have a perspective on my body. If I did, I would require a second body, or perhaps a homunculus that would act as an index. Thus, as Bermudez admits, there is a "fundamental disanalogy between the bodily space of proprioception and the egocentric space of perception and action" (1998, p. 152)

We have argued that proprioception in its most typical form, that is, as prereflective and attentionally recessive, is not equivalent to body perception', it is not the image, the representation, or even a consciousness of the body as an object in the periphery of the perceptual field. Rather, it functions as a nonperceptual element in the structure of perception, but is not itself a form of perception.

\section{In defense of the immunity principle}

To understand why it is important to consider proprioception a form of nonperceptual awareness, we need to examine a particular issue concerning selfreference. Numerous authors (e.g., Wittgenstein, 1958; Strawson, 1994; Shoe- 
maker, 1968; Evans, 1982) have argued that certain forms of self-reference are immune to error through misidentification. ${ }^{8}$ I will refer to this as the "immunity principle." The idea, as explained by Wittgenstein, is that in using the first- person pronoun I cannot be mistaken in regard to whom it refers. If I say "I think it will rain today," I can be wrong about the rain, but I can't be wrong about who is doing the thinking. In this case the T acts "as subject," as the thinker of the thought.

Wittgenstein thought, however, that in some cases - one could misidentify oneself. It is quite possible to misidentify one's body, for instance. I may look into a mirror and think I see my hand, when in fact it is actually someone else's hand, and I end up being in error about myself. If the hand has a bruise on it I might say, "I'm bruised," and thereby make a mistake in self-reference. In that case, however, the way I know myself is through a visual perception which takes the mirror image as an object. Wittgenstein provided examples like this, and claimed that we can misidentify ourselves if our access to ourselves is "as object." His version of the immunity principle, then, states that we cannot misidentify ourselves if our access to ourselves is "as subject."

Strawson suggests a stronger version of the immunity principle. He claims that all uses of the first-person pronoun are in fact "as subject." If I look in the mirror and say, "I'm bruised," on the basis of seeing a bruised hand, but the hand is actually someone else's hand, then I can say I made a mistake - my hand is not bruised. But this is a mistake only because I have used the first-person pronoun to refer to myself, and have not misidentified myself. Whenever I say T, I refer to no one other than myself. Even when I mistakenly refer to myself as the person who has a bruise on his hand, I am still self-referring in the proper way, and indeed, I am in error in some respect only because I have correctly self-referred. My statement "I'm bruised" would not be incorrect in the way that it is unless the "I" referred to myself. And if I discovered my mistake I might say "Oh, it is not $I$ who am bruised." Both of these statements have their proper meaning only if the "I" refers to me. In such cases, it is precisely myself about whom I am wrong. But this is not an error of misidentification. If this is so, then Wittgenstein's distinction between as subject and as object is irrelevant to the immunity principle.

In agreement with several other authors (Bermudez, 1998; Cassam, 1995; Evans, 1982) I want to claim that somatic proprioceptive awareness allows for a self-reference that is immune to error through misidentification. For this to be the case, however, proprioceptive awareness cannot be a form of perception.

\footnotetext{
${ }^{8}$ This is most often understood as involving the use of the first-person pronoun, although it need not involve that pronoun.
} 
The immunity principle depends on the idea that our mode of access to ourselves does not involve a process of identification, a criterial judgment about which we could be wrong. If proprioception did involve identification, if it involved keeping track of the body in the same way that we keep track of objects, then it would be quite possible to make an error of misidentification based on our proprioceptive self-awareness.

Although Strawson's stronger version of the immunity principle may be the case with respect to the first-person pronoun, I will argue that in regard to bodily self-awareness and its possible immunity to error through misidentification, it is important to retain Wittgenstein's distinction between 'as subject' and 'as object', and to maintain that proprioception is not a fonn of perception.

Evans (1982) and Cassam $(1994,1995)$ have argued that bodily selfascription based on proprioceptive awareness is immune to error through misidentification. By bodily self-ascription they mean being able to know that one instantiates a given bodily property, such as being in pain, being hot, or sitting with one's legs crossed. In cases where one knows the latter sort of property (that is, a postural property) by vision, e.g., when one looks in the mirror, it is clearly possible to be wrong. But when one knows a postural property by proprioception, "from the inside" as it were, then one is immune to error through misidentification. If my knowledge is of the proprioceptive sort, then I cannot say that my legs are crossed and be wrong about whose legs are crossed, or be wrong about fact that they feel crossed. But am I necessarily correct about my legs actually being crossed?

We do have to be careful here, and in this case being careful means distinguishing between objective self-reference and subjective self-reference. The claim cannot be that through proprioception we cannot be mistaken about whether or not our legs are crossed objectively. Proprioception can be fooled in this regard. Experiments that involve the vibration of certain muscles can lead a subject to say that his arm or leg is in position A when in fact, that is, objectively, it is in position B (see Lackner, 1988). Proprioceptively we can be in error about where our arm is, or in the case of phantom limb, that there is an arm there at all. So the argument is not that proprioception is immune to error through misidentification because it necessarily delivers veridical information about objective limb position. In the same way that we can be wrong about the rain in the sentence $T$ think it is going to rain', we can be wrong about the objective posture of our body. Proprioception is immune to error through misidentification, however, because it necessarily provides a form of non-observational access to the first- person, "ipseic" experience of embodiment - that is, it provides a sense of ownership (see Gallagher, 2000a) for the body and its movements. The immunity principle pertains to the first-person (subjective) experience of ownership rather than to the objective or spatial content of proprioception. What is sure in 
proprioceptive experience is the ipseity of the primitive first-person experience of embodiment that is a basic part of the self - non-self distinction. If I say that my legs are crossed, I can't be wrong about them being mine.

To challenge this claim, however, Armstrong, Shoemaker and others propose a thought experiment. Consider the idea that one might link up brain A with body $\mathrm{B}$ in such a way that proprioceptive information about body B is delivered to A so A could think his legs are crossed, when in fact B's legs are the ones crossed. ${ }^{9}$ The real issue here is not about legs being crossed, or not, but about whose legs are whose. To answer this unusual state of affairs one needs to be more specific: proprioception provides a sense of ownership for the lived body (not necessarily the objective body). In most normal situations, the lived body coincides with the objective body. In the case of the thought experiment where brain A is linked up with body $\mathrm{B}$, the body that is lived and experienced by $\mathrm{A}$ includes the proprioceptive aspects of body B, even if objectively speaking body B is not A's body.

Evans expresses the immunity principle for proprioception by the following question, which he identifies as nonsensical: "Someone's legs are crossed, but is it $m y$ legs that are crossed?" It is clear that even by proprioception I may be wrong about the objective position of my limbs. But if one defines $m y$ limbs as the limbs that I am experiencing - the limbs that are part of my lived body - I may be wrong both about their position and about them being my legs objectively, but I cannot be wrong about the "mineness" (the sense of ownership) that is part of the structure of bodily experience. ${ }^{10}$

Although Cassam (1995) and Evans (1982) want to defend the idea that proprioception is governed by the immunity principle, they nonetheless suggest that proprioception is a form of awareness of oneself as an object. From our considerations above, this seems incorrect. Of course, as we have seen, it is possible to have a perceptual awareness of the body that refers to the body as to an object. This may be the result of a perceptual act that attends to the body as its explicit object, as in a reflective proprioception, or visually, as in a reflective mirror. This kind of perception picks the body out (identifies it) as the object to focus on, and in so doing it explicitly discriminates between the body and other objects in the environment. In this regard, an act of perception that involves an identification constraint, that is, that picks out or identifies its object from among other objects, cannot be immune to error through misidentification.

The immunity principle, as Shoemaker suggests, depends on the idea that our immediate access to ourselves does not involve a process of identification,

9 See Evans' discussion of this thought experiment (Evans, 1982).

${ }^{10}$ Also see Cole, Sacks, and Waterman (2000) and my response, Gallagher (2000b), on this issue. 
a criterial judgment about which we could be wrong. If proprioception did involve identification, if it involved keeping track of the body in the same way that we keep track of objects, then it would be quite possible to be in error in our proprioceptive access to ourselves. Normally, when my attention is directed at some object in the environment, my proprioceptive awareness of my body is precisely not an identifying awareness of it as an object. That is, it is not an objective perceptual awareness. In its most typical form, proprioception's prereflective reference to the body is as subject, as actor, or as existing within the act of perception, rather than as object perceived.

Proprioception, in its most typical form, as this pragmatic (action-oriented) pre-reflective awareness, but not in its involuted form, is immune to error through misidentification precisely because it does not take the body as an object. It is therefore necessary to retain the Wittgensteinian distinction between as subject and as object in this context. In contrast to the objective self-reference of an involuted, reflective proprioceptive perception, subjective (pre-reflective and nonobservational) proprioceptive self-awareness is immune to error through misidentification.

\section{References}

Armstrong, D. M. 1968. A Materialist Theory of the Mind. London.

Bermudez, J. L. 1998. The Paradox of Self-Consciousness. Cambridge: MIT Press.

Bermudez, J. L. 1995. Transcendental arguments and psychology: The example of O'Shaughnessy on intentional action. Metaphilosophy, 26: 379-401.

Bermudez, J. L., A. Marcel, and N. Eilan. 1995. The Body and the Self. Cambridge, MA, MIT Press.

Cassam, Q. 1995. Introspection and bodily self-ascription. In J. Bermudez, A. J. Marcel, and

N. Eilan (eds.), The Body and the Self (pp. 311-36). Cambridge: MIT Press.

Cassam, Q. 1994. Introduction. In Q. Cassam (ed.), Self-Knowledge (pp. 1-18). Oxford: Oxford University Press.

Chisholm, R. 1969. On the observability of the self. Philosophical and Phenomenological Research, 30: 7-21.

Cole, J. D., Sacks, O. and Waterman. I. 2000. On the immunity principle: a view from a robot. Trends in Cognitive Science, 4 (5): 167.

Evans, G. 1982. The Varieties of Reference, ed. J. McDowell. Oxford: Oxford University Press.

Fouumeret, P. and Jeannerod, M. 1998. Limited conscious monitoring of motor performance in normal subjects, Neuropsychologia 36: 1133-1140.

Gallagher, S. 2000a. Philosophical conceptions of the self: implications for cognitive science. Trends in Cognitive Science, 4(1): 14-21.

Gallagher, S. 2000b. Reply to Cole, Sacks, and Waterman. Trends in Cognitive Science 4. No. 5 (2000): 167-68. 
Gibson, J. J. 1979. The Ecological Approach to Visual Perception. Boston: Houghton- Mifflin.

Kinsboume, M. 1995. Awareness of one's own body: An attentional theory of its nature, development, and brain basis. In J. Bermudez, N. Eilan, and A. Marcel (eds). The Body and the Self (pp. 206-223). Cambridge, MA: MIT Press.

Lackner, J. R. 1988. Some proprioceptive influences on the perceptual representation of body shape and orientation. Brain, 3: 281-297.

Merleau-Ponty, M. 1962. Phenomenology of Perception, trans. C. Smith. London: Routledge and Kegan Paul.

Neisser, U. 1988. Five kinds of self-knowledge. Philosophical Psychology, 1: 35-59.

O'Shaughnessy, B. 1995. Proprioception and the body image. In J. Bermudez, A. J. Marcel, and N. Eilan (eds). The Body and the Self (pp. 175-203). Cambridge, MA: MIT Press.

O'Shaughnessy, B. 1989. The sense of touch. Australasian Journal of Philosophy, 67: 37-58.

O'Shaughnessy, B. 1980. The Will: A Dual Aspect Theory. Cambridge: Cambridge University Press.

Sartre, J-P. 1956. Being and Nothingness: An Essay on Phenomenological Ontology, trans. H. E. Barnes. New York: Philosophical Library.

Sheets-Johnston, M. 1998. Consciousness: A Natural History, Journal of Consciousness Studies, 5 (3): 260-94

Sherrington, C. 1953. Man on His Nature, 2nd ed. New York: Doubleday.

Shoemaker, S. 1994. Self-knowledge and 'inner sense'. Philosophy and Phenomenological Research, 54: 249-314.

Shoemaker, S. 1986. Introspection and the self. In P. A. French, T. E. Vehling and H. K. Wettstein (eds). Studies in the Philosophy of Mind (pp. 101-120). Minneapolis. Midwest Studies in Philosophy, Vol. 10.

Shoemaker, S. 1984. Identity, Cause, and Mind. Cambridge: Cambridge University Press.

Shoemaker, S. 1968. Self-reference and self-awareness. Journal of Philosophy, 65: 555-67.

Strawson, P. F. 1994. The first person - and others. In Cassam, Q. (ed.). Self-Knowledge (pp. 210-215). Oxford: Oxford University Press.

Trevarthen, C. B. 1986. Neuroembryology and the development of perceptual mechanisms. In F. Falkner and J. M. Tanner (eds). Human Growth: A Comprehensive Treatise, $2^{\text {nd }} \mathrm{ed}$. (pp. 301-383). New York: Plenum Press.

Wittgenstein, Ludwig (1958). The blue and brown books. Oxford: Basil Blackwell. 